\title{
Estimation of synchronous generator participation in low-frequency oscillations damping based on synchronized phasor measurements
}

\author{
P. Y. Kovalenko, Y. P. Zakharov \& A. S. Berdin \\ Department of Automated Electrical Systems, \\ Boris Yeltsin Ural Federal University, Ekaterinburg, Russia
}

\begin{abstract}
Large-scale centralized power systems interconnected by weak tie-lines is a typical feature of the state-of-the-industry power engineering. Another trend is distributed generation units integration with the resulting decrease of power system inertia constant and increasing sensitivity to small disturbances. In particular, in the case of significant power imbalance, periodic low-frequency oscillations of power system performance parameters may arise. Lowfrequency oscillations in power systems are inherently non-linear and nonstationary processes representing a superposition of numerous rotating masses movement components having mutual influence in a power region or power center. These situations imply the crucial role of monitoring each generator damping capability which is determined by the adjustment of the system regulators in use.

To estimate the synchronous generator capability to maintain synchronous operation under deviating frequency and load angle conditions synchronizing torque and corresponding synchronizing power are proposed to be used. The possibility to determine the synchronous machine synchronizing power is subject to the presence of the load angle variation data with the techniques for defining load angle without direct measurement using a system of assumptions have been analyzed. Numerous simulations have shown that the effect of assumptions can be evaluated as acceptable.

The main focus of the paper is the analysis of synchronizing power corresponding to the actual generator involved in the oscillations which had
\end{abstract}


arisen after a disturbance in the Unified Energy System of Russia. The supposed cause of the oscillations is improper automatic excitation controller operation.

Keywords: low-frequency oscillations, phasor measurements, synchronous generator, generator load angle, synchronizing power.

\section{Introduction}

Low-frequency oscillations (LFO) of power system performance parameters during electromechanical transient processes conventionally result from the following situations:

- decreasing or increasing frequency due to power generation and consumption imbalance occurrence in certain power region;

- $\quad$ asynchronous operation of several power system parts;

- $\quad$ power system separation;

- congestion of intertie and through-connection transit power lines;

- improper adjustment of power system regulators (automatic excitation controller, automatic turbine speed controller).

The resonance frequencies (eigen frequencies) of the power system and the frequencies of the power stations integrated to form a power region are individual but each of them represent different low-frequency components corresponding to mutual movement of certain parts of power systems or even whole power systems and natural frequencies of power stations generators.

Low-magnitude generators oscillations are taking place essentially all the time due to continuously power generation and consumption imbalance arising resulting in negligible frequency changes in power regions [1]. These oscillations are well damped and do not threaten power system stability. However in case of significant power imbalance in power systems periodic frequency deviations with magnitude in excess of $0.05 \mathrm{~Hz}$ may arise. These situations imply the crucial role of monitoring each generator damping capability which is determined by the adjustment of the system regulators in use.

\section{The concept of synchronizing power as a measure of the generator damping capability}

It is appropriate to adopt the quantity of energy spent by the generator on the counteraction of the rotor slip relative to the system frequency as a measure of damping qualities of the generator. This quantity is referred to as synchronizing energy and is considered during the interval corresponding to the period of electromechanical oscillation process.

To estimate the synchronous generator capability to maintain synchronous operation under deviating frequency and load angle $\theta$ conditions synchronizing torque $\partial M / \partial \theta$ and corresponding synchronizing power $\partial P / \partial \theta$ are to be used [2].

Synchronous generator synchronizing energy corresponding to one period of LFO is determined by 


$$
W_{s p}=\int_{p s}^{p e} P_{s}(t) \mathrm{d} t,
$$

where $P_{s}(t)$ is synchronizing power at the moment $t, p s$ and $p e$ are period starting time and period ending time, correspondingly.

Synchronizing energy corresponding to the whole time of LFO existence is defined as a sum of all $W_{s p}$ corresponding to single periods of oscillations.

Assuming the absence of magnetic losses and electrical losses in armature winding which are negligible in state-of-the-industry synchronous generators the quantity of electromagnetic power is equal to active power of the generator $P_{e m}=P_{g}$ [2]. Having direct synchronized phasor measurements of active power and the load angle of the generator the synchronizing power at unspecified moment $t$ is defined as

$$
P_{s}(t)=\frac{\partial P_{e m}(t)}{\partial \theta(t)} .
$$

If system regulators are adjusted properly the synchronizing power always impedes changing power system frequency applying the synchronizing torque to decrease the difference between system frequency $f_{s}$ and rotor frequency $f_{r}$.

Influence of the automatic excitation regulator of the synchronous generator involves changing $P_{e m}(t)$ and may be derived from excitation current $I_{f}(t)$ measurements together with stator voltage $U_{g}(t)$ and current $I_{g}(t)$ :

$$
I_{f}(t) \rightarrow U_{g}(t) * I_{g}(t) \rightarrow P_{e m}(t) .
$$

To define the quantity of synchronizing torque and synchronizing power corresponding to the actual synchronous machine operating conditions at predefined moment $t$ the value of load angle $\theta$ is necessary.

Although technology of synchronized phasor measurements allow measuring the generator load angle as well as excitation voltage and current directly, measuring devices in use (in the Unified Energy System of Russia) do not support these functions. This paper describes the method that can be used in case of absence of direct measurements and implies deriving the load angle from the equations corresponding to the vector diagrams of the synchronous machine. The basic assumption is that load angle deviations $\Delta \theta$ are small, then

$$
\sin (\Delta \theta) \cong \Delta \theta=\theta-\theta_{0} .
$$

In this situation experimental or design-specified parameters of the generator can be used to determine the load angle according to the following expression:

$$
\theta=\operatorname{arctg}\left(\frac{X_{q} I_{q}-R I_{d}}{E_{f}-X_{d} I_{d}-R I_{q}}\right),
$$

where $\theta$ is the angle between excitation electromotive force $E_{f}$ and voltage vector $U$; 
$E_{f}$ - excitation electromotive force, induced in the phase of armature winding by the mutual inductance field produced by excitation magnetomotive force; $X_{q}, X_{d}$ - full inductance along the quadrature axis and the direct axis, respectively;

$I_{q}=I \cos (\beta), I_{d}=I \sin (\beta)$ - quadrature and direct phase armature winding current vector $I=I_{d}+j I_{q}$ components;

$R$ - resistance of the phase of armature winding.

Numerous simulations have shown that the effect of assumptions can be evaluated as acceptable [3].

\section{Practical example of synchronizing power assessment}

As an example of applying the proposed method participation of turbogenerating set with the nominal power of $800 \mathrm{MW}$ in damping the oscillations was assessed. The oscillations arose after a disturbance in the Unified Energy System of Russia [4]. Since the set of registered parameters was limited to stator voltages and currents the proposed method was applied.

The graph of the active power of the generator is represented at fig. 1. Fig. 2 shows the obtained relation between the generator active power and its load angle for one period of LFO of marked intervals.

Moreover, the oscillation process itself proved to be highly non-linear. Fig. 3 presents the non-linearity of the process compared to the sinusoidal oscillation of corresponding frequency and magnitude which are specified for every single period of oscillations. The process is zero-centered to provide better visualization. It can be seen that the positive half-period of actual oscillations is wider than the negative one.

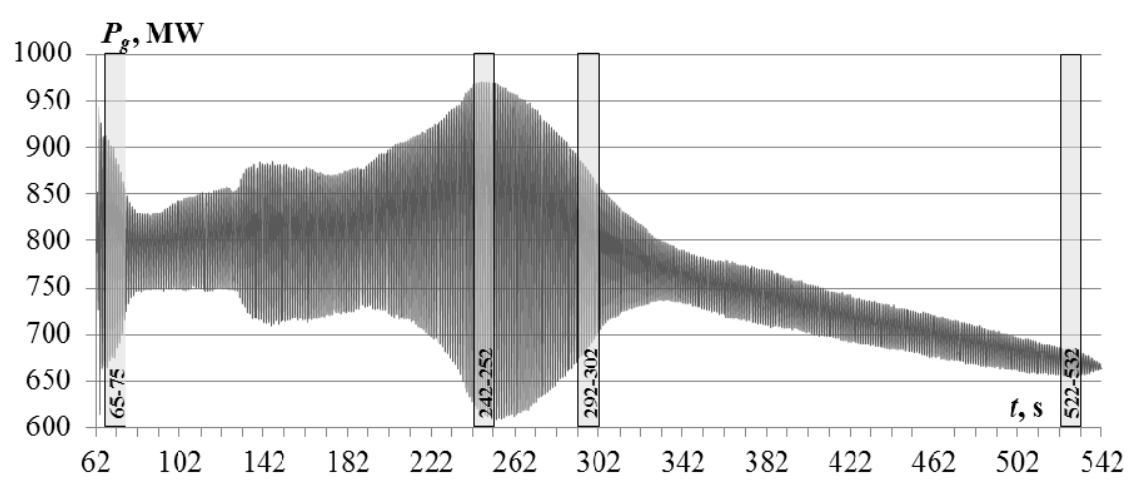

Figure 1: Generator active power oscillations. 


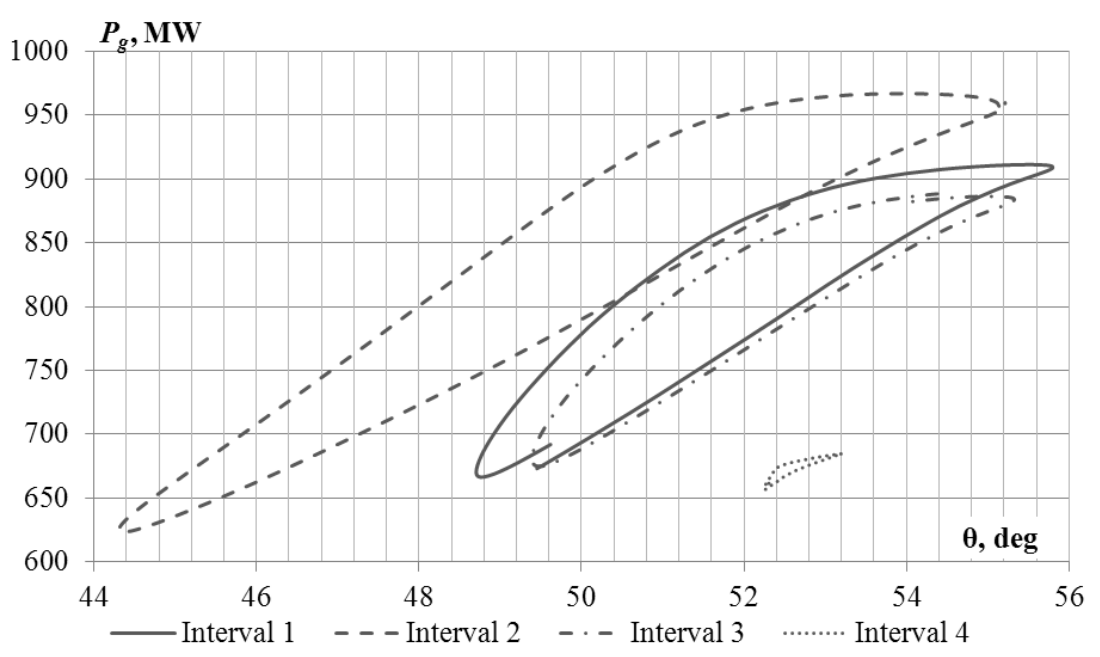

Figure 2: $\quad$ Relation between the generator active power and its load angle.

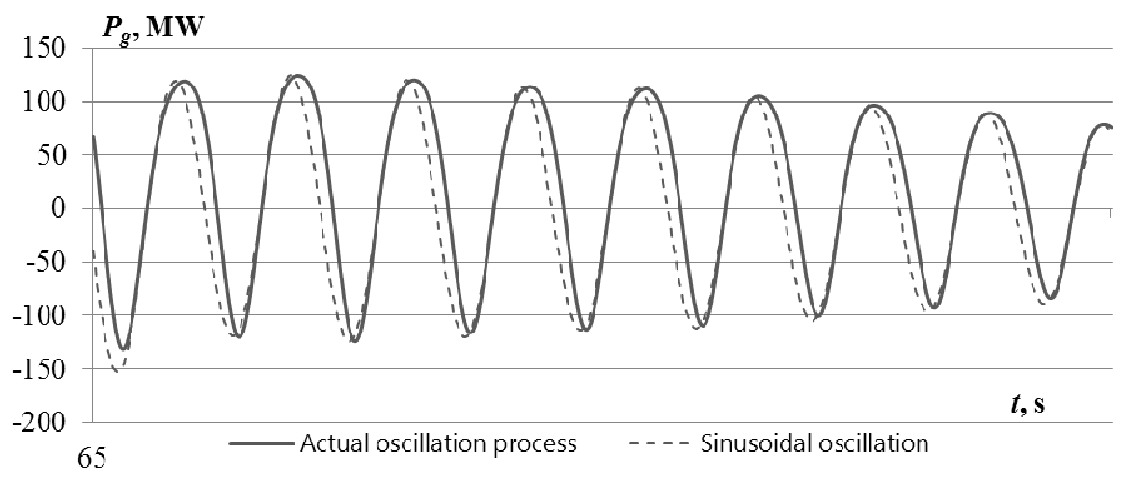

Figure 3: Non-linearity of actual low-frequency oscillations process.

The following quantities were determined for four 10-second intervals marked on the fig. 1:

$P_{g}^{\text {mean }} \quad$ - mean value of the generator power;

$P_{g}^{\min } \quad$ - minimum value of the generator power;

$P_{g}^{\max } \quad-$ maximum value of the generator power;

$\theta^{\text {mean }} \quad-$ mean value of the generator load angle; 


$$
\begin{array}{ll}
\theta^{\min } & \text { - minimum value of the generator load angle; } \\
\theta^{\max } & \text { - maximum value of the generator load angle; } \\
P_{\text {sync }}^{\text {mean }} & \text { - mean value of synchronizing power (per degree); } \\
P_{\text {sync }}^{\min } & \text { - minimum value of synchronizing power (per degree); } \\
P_{\text {sync }}^{\max } & \text { - maximum value of synchronizing power (per degree). }
\end{array}
$$

The results are presented in table 1.

Table 1: Results of the generator active power low-frequency oscillations.

\begin{tabular}{|l|c|c|c|c|}
\hline Interval & $\mathrm{I}_{1} 65 \mathrm{~s}-75 \mathrm{~s}$ & $\mathrm{I}_{2} 242 \mathrm{~s}-252 \mathrm{~s}$ & $\mathrm{I}_{3} 292 \mathrm{~s}-302 \mathrm{~s}$ & $\mathrm{I}_{4} 522 \mathrm{~s}-532 \mathrm{~s}$ \\
\hline$P_{g}^{\mathrm{mean}}, \mathrm{MW}$ & 804.53 & 835.08 & 798.59 & 670.76 \\
\hline$P_{g}^{\min }, \mathrm{MW}$ & 664.16 & 610.13 & 674.95 & 654.57 \\
\hline$P_{g}^{\max }, \mathrm{MW}$ & 913.47 & 970.99 & 890.66 & 684.73 \\
\hline$\theta^{\text {mean }}, \operatorname{deg}$ & 52.37 & 50.13 & 52.65 & 52.66 \\
\hline$\theta^{\min }, \operatorname{deg}$ & 48.57 & 43.63 & 49.39 & 52.17 \\
\hline$\theta^{\max }, \operatorname{deg}$ & 55.90 & 55.50 & 55.57 & 53.21 \\
\hline $\begin{array}{l}P_{\text {sync }}^{\mathrm{mean}}, \\
\mathrm{MW} / \mathrm{deg}\end{array}$ & 36.60 & 26.15 & 34.82 & 41.06 \\
\hline $\begin{array}{l}P_{\text {sync }}^{\mathrm{min}}, \\
\mathrm{MW} / \mathrm{deg}\end{array}$ & -5.33 & -22.40 & -0.95 & -12.69 \\
\hline $\begin{array}{l}P_{\text {sync }}^{\mathrm{max}}, \\
\mathrm{MW} / \mathrm{deg}\end{array}$ & 94.92 & 49.12 & 94.89 & 131.78 \\
\hline
\end{tabular}

Mean synchronizing power per degree characterizes the amount of energy applied to damping the oscillation process by the generator. The least value of $P_{\text {sync }}^{\text {mean }}=26.15 \mathrm{MW} /$ degree was obtained at the interval of maximum oscillations magnitude. After unloading generator the value have increased up to $34.82 \mathrm{MW} /$ degree and has reached $41.06 \mathrm{MW} /$ degree at the end of oscillation process. 


\section{Conclusions}

The conclusion after the analysis of synchronizing power is that under insufficient measurements conditions it is still possible to qualitatively evaluate the development of the oscillations process along with the corresponding evaluation of the system regulator performance in terms of damping the oscillations. Moreover, with enough direct measurements the approach to the online generator oscillations control is clearly the short-time perspective.

\section{References}

[1] Ayuev B.I. Metody i modeli effektivnogo upravleniya rezhimami Yedinoy elektroenergeticheskoy sistemy Rossii [Methods and Models for Efficient Operational Control of United Power System of Russia]. D.Sc. thesis in engineering science. Yekaterinburg, 2008.

[2] Ivanov-Smolenskiy A.V. Elektricheskiye mashiny: uchebnik dlya studentov vuzov, obuchayushchikhsya po napravleniyu podgotovki diplomirovannykh spetsialistov «Elektrotekhnika, elektromekhanika $i$ elektotekhnologii» [Electrical Machinery: High School Student Textbook for Those Studying at Certified Specialists Training Course]: in 2 volumes. / A.V. IvanovSmolenskiy. 2nd edition, revised and enlarged. Moscow: MEI, 2004.

[3] Y.P. Zakharov, P.Y. Kovalenko. Identifikaciya nizkochastotnyh kolebaniy $v$ elektroenergeticheskoy sisteme [Identification of Low-Frequency Oscillations in Power System]. Zhurnal «Nauchnoe obozrenie»["Science Review” Magazine] №12, 2013.

[4] Pavlushko S.A. Avtomaticheskoe regulirovanie vozbuzhdeniya sinhronnyh generatorov kak effektivniy instrument obespecheniya nadezhnosti parallelnoy raboty generiruyushchego oborudovaniya $i$ EES $v$ celom [Synchronous Generators Automatic Excitation Regulation as an Effective Instrument for Providing Reliable Synchronous Operation of Generating Equipment and the Unified Energy System of Russia in general]. Zhurnal «Elektricheskie Stantsii» [“Power Plants” Magazine]. Moscow, №07/2012. 